drawn to the right, will cut the first or vertical line just below the tip of the ensiform cartilage, and complete what I would venture to call the lower tricuspid triangle, or the area within which tricuspid stenosis murmurs are chiefly audible. I use the term "lower" because a similar figure might in like manner be drawn rather above and to the right of this which would cover the area of tricuspid regurgitant murmurs. I am aware that this is not only a smaller space, but greatly diverse in position from that assigned to general tricuspid murmurs by a great authority, Professor Gairdner of Glasgow. It is also rather different and somewhat smaller than that given by a very careful clinical teacher, Dr. Hayden of Dublin, after a thoughtful review of three well-marked cases. But, with all deference to these very accurate observers, I am inclined, after a somewhat careful review of these 32 cases, to believe that the above defined area is mainly correct, especially as, after deducing the triangle from the facts, I found that its highest point lies almost exactly over the tricuspid orifice, and that it covers the course which the blood must take on being propelled downwards from this opening towards the apex of the right ventricle. With regard to the murmurs heard, the mechanism of the cardiac cycle, the analogy of tricuspid and mitral stenoses, and the fact that a presystolic murmur is pathognomonic of the latter disease, justify, I think, the assertion that the former may also, and probably does, produce a bruit heard during the cardiac pause. And this is proved by the fact that the disease has been diagnosed during life from the presence of this one sign by Dr. Hayden and Foster, and that in 11 out of 32 cases there was a well-marked harsh, presystolic bruit heard during life within the lower tricuspid triangle.

A. Diagnosis.-The presence, however, of this murmur in this area does not necessarily mean the existence of true orificial stenosis. Professor Gairdner diagnosed tricuspid obstruction from this one physical sign in a man in 1862 . Ten years afterwards the man died, and obstruction of the tricuspid was found, not from any disease of the valves, not from any change in the orifice, but from the presence of a small globular pedunculated tumour of the auricular wall, which descended into the aperture after the manner of a ball valve. Again, Dr. Ernest Sansom informs me that a patch of roughening on the pericardial surface of the right auricle may give rise to a rubbing sound audible in the lower triouspid triangle, and simulating a presystolic murmur even to the most practised ear. To summarise then the diagnostic features of this disease, I think it may be asserted that-

1. If there be clear evidence of mitral stenosis, which exists in every case of the analogous tricuspid condition, a well-marked murmur in the lower tricuspid triangle, if it be harsh in tone, and especially if it be presystolic in time, the patient an adult female, the systemic venous circulation more embarrassed than the pulmonary, and the right auricle much dilated, there is probably stenosis of the tricuspid.

2. If the same signs be present in a man, and the murmur in the lower tricuspid triangle be very clear, or very clearly distinct from that at the apex, and plainly presystolic in time and tone, the disease is tricuspid stenosis. If the latter conditions be not well marked it is probably a case of tricuspid regurgitation.

3. If there be a distinct presystolic murmur at the apex, not much systemic venous obstruction, and no evidence of mitral stenosis, the bruit is caused by some congenital malformation of the tricuspid valves, or due to roughening of those valves, to the presence of some such condition as found in Professor Gairdner's case, or to a patch of pericardial roughening localised to the right auricle.

4. If the patient be a female, has suffered much from acute rheumatism, is known to have previously exhibited signs of mitral stenosis, has great dilatation of the right auricle, a feeble cardiac action and greater systemic than pulmonary venous obstruction, even though no murmur be heard at all, or only a faint systolic bruit be audible, tricuspid stenosis may be present to an extreme degree.

(To be concluded.)

Dental Examinersmip. - It is stated that the Committee on Examinations in Anatomy and Physiology of the Royal College of Surgeons will meet on Monday next to consider and report to the Council on the applications and nominations of "persons skilled in dental surgery."

\section{CASE OF MYXEDEMA.}

BY HENRY A. LEDIARD, M.D., F.R.C.S., SURGEON TO THE CUMBERLAND INFIRMARY, LATE MEDICAL SLPEP INTENDENT TO THE CENTRAL LONDON SICK ASYLCM,

$$
\text { CLEVELAND-STREET, W. }
$$

ELLEN D—, aged fifty-four, was admitted into tile Cleveland-street Infirmary, London, on August 26th, 18, during my absence from home. She was being treated for dropsy, and $I$ found this note taken, that the abdomen appeared to be ascitic, but gave no fluid wave on percussion, There was no albumen in the urine, and the patient had remained neither better nor worse.

From the description Dr. Ord gave of the disease in a paper read at the Clinical Society, early in the session 1879-80, I a once came to the conclusion that the patient under mv care who was being treated for dropsy, was the subject of myxodema. I say from his description, for I did not see the patient shown on that occasion; indeed, this is nearly the first case I have seen; one other that I can recollect occurred in Edinburgh. I did not attend the lady, but I well remember her features and manner, which are so very characteristic of the disease. I mention this case in addition to the one I an about to give, because they were both women in somewhat advanced years.

The patient states that she was born in Tipperary; her mother died at sixty (disease?), her father died at forty of fever. There were wine children; the patient is the eldest, two only remain beside herself, the rest died under fifteen years She had always been healthy until she "got the dropsy, nine months before, when the skin became rough and peeled off, together with weakness in the back and breathlessness on mounting stairs. She has been married and has had eleven children; six died young, and the five living are twelve, nineteen, twenty, twenty-three, and twenty-nine years respectively. Her husband was gouty. She could mever write, but can read a paper. Has been a charwoman of late. It was difficult to get much history from the patient, but slie did her best, so I tried her relations. Her son-in-law had known her for seven years. She was always a slow speaker, but he thinks she is slower in speech now. She is not $s 0$ hasty in temper as she used to be, and her voice is deader than formerly. Another person said she had known the patient for eight years. She was always stout and slow in mannes, but she looks yellower than formerly and speaks slower, and she cannot understand her so well as before. For some reason I could not induce a daughter to come and be questioned.

The case so closely resembles Dr. Ord's very graphic description that I think I need not give all the clinical features at length, but add that it was noted that the face was puffed and waxy-looking, with a delicate colouring of the cheeks, lips somewhat pouting, no expression, and when the patient smiled the eyes almost disappeared. The tongte was characteristic, being large and flabby; there was often observed an oedematous swelling of the uvula and soft palate. The patient in disposition was quiet and cheerful certainly very slow of understanding, for to every question she always answered, "What's that, doctor?" As an example of her disposition, I remember that on one occasion a medical friend asked her to show her teeth; she said slowly, "I haven't got none, doctor," and seemed highly amused at the joke. Her chief occupation was knitting stockings, but the needles worked slowly. She took part in the ordinary work of the ward, such as helping the nurse; and I never saw her out of temper for the eight months that she was under my constant observation. She was somewhat inclined to sleep, and occasionally was found nodding in her chair.

As to the thyroid gland, the neck was too fat to enable anyone to say whether it was small, or even present. Occasionally there were glandular enlargements in the neck, below the jaw and above the clavicle, these swellings being usually preceded by well-marked rigors. Back pain wa tolerably constant. The skin was always dry, harsh, and rough, not more so on the hands and arms (she had been washerwoman) than elsewhere. The hair on scalp was plentiful, and black. In order to test the skin I experimented with pilocarpin injected hypodermically. (in December 22nd a quarter of a grain was given, the next day half a grain, without result; but on the $2 S$ th one grain acted in a few moments, and she began to wipe her face. The nurse reported that the sweating was general and lasted one hour and a half, no inconvenience being complained of, 
the patient saying that "there was more water in her mouth."

On December 30th the note runs: "Skin unaltered by the sweating. Extensive area of ecchymosis near pin puncture in a vein." On November $12 \mathrm{th}$, also, it was noted that a pin scratch on her chin had produced some subcutaneous ecchymosis in its track of unusual character.

The odema was general, and really was not œdema proper, for it orly pitted on firm and rather prolonged pressure, very differently from what is seen in ordinary dropsy. The urine was never found to contain albumen, was repeatedly examined, the quantity passed was natural, and the colour always pale; minute analysis was never gone into. The blood I began to examine with the hrmacy tometer, but on my resigning my appointment this was in an unfinished state. I made repeated examinations with the ophthalmoscope, but nothing abnormal was seen; the media were exceptionally clear, and pupils well dilated with atropin or duboisin. The laryngoscope found the larynx and vocal cords quite natural. The examination of the vagina and cervix was intended but never accomplished; in one of Dr. Ord's cases the vulva, os uteri, rectum, and anus were noted as showing change. Sight. smell, taste, and hearing were not noticeably altered in any way, neither was any bloody urine observed. The hands were as Sir W. Gull has described them-swollen, broadened, and shapeless, but this may have been accidental, seeing that she was a stumpy, clumsy woman generally. The abdomen was flabby and pendulous, always looked ascitic, but no fluid was ever detected by percussion. The temperature was recorded from October 29th, 1879, to November 18th; one thermometer was used, and from then until April 27th, 1880, two were used twice daily in each armpit without a single intermission, nurse Westell taking the greatest care and interest in these observations, for which she deserves the order of St. Katherine. There was never any marked difference on the two sides, the up and down strokes corresponding nearly exactly. The average temperature was $95^{\circ}$ and $96^{\circ} \mathrm{F}$.; $97^{\circ}$ was reached forty-one times in eight months, $98^{\circ}$ five times, and the temperature was above normal once only, when on November 2nd it was $99^{\circ}$. The note taken was: "Pain and swelling in throat inside and out, and on the following day fauces odematous." This rise may have been due to some catarrh. I regard, then, this constant subnormal temperature as very characteristic and remarkable.

During the eight months she had fits once, on Feb. 22nd. The notes run thus: "Seems dull and heavy this morning, having had two fits yesterday. She stated that previously there was pain in her heart, her sight left her, and she felt faint." There was nothing unusual observed about the size of the heart and its action. The lungs were healthy, and no increase in size was found in liver or spleen. The digestive organs acted well. She never vomited, and had always a moist clean tongue. Her diet was a plain one always, and she was easy to please in this respect. Several medicines were given by mouth, such as diuretics, but without any result, and, as far as I noticed, she was not markedly worse at the end of eight months than she was at the commencement. Her mental state I cannot give better than as described by Sir W. Gull as that of "senile placid indifference." There was no syphilitic history. I have nothing to place on record of the pathology of this disease at present, but Dr. Ord has given the results of examinations in some of his cases, which terminated in the usual manner.

The case in point was shown, as occasion permitted, to several medical men, amongst whom were Mr. Hutchinson, Dr. Barlow, and Dr. Douglas Powell, who quite agreed with me as to diagnosis.

Carlisle.

\section{A NEW SPLINT FOR THE ARM.}

\section{BY NORMAN PORRITT, L.R.C.P. LOND.,} HOUSE-SURGEON TO THE HUDDERSFIELD INFIRMAARY.

THE splint figured below consists of a flat piece of iron moulded at one extremity to fit the shoulder, and at the other to support the hand. It procures complete immobility of the elbow-joint, while possessing the following advantages orer the wooden rectangular splints used for that purpose :-

The splint is not bandaged to the limb, and there is, therefore, no fear of tight bandaging and its attendant evils, cir- culation being in no way interfered with. There is sufficient space between the elbow and the splint to apply any dressings, antiseptic or otherwise, without removing the splint or disturbing the position of the limb. It acts as a sling by supporting the arm, and although movement of the whole arm is allowed, no movement at the elbow is possible.

In applying, the bandage is carried across the back over the opposite shoulder, round the front of the chest, again to the back, where it passes horizontally between the end of the splint and the bandage over the shoulder, once round the body, when it is tied behind. The end of the splint is thus prevented from moving outwards or upwards, and in practice it is found that the splint keeps its position. The splint is light and cheap, and can be made by an in. telligent blacksmith, the length of the shoulderpiece being ten inches, of the shaft eleven inches, and the support for the hand measures six inches. If made of soft iron, the comparative lengths of the shaft and shoulder-piece can be altered by bending to suit different-sized individuals, and with a little padding for the hand and sloulder-pieces the splint is complete. Mr. A. Kempner, of Woodhouse-lane, Leeds, has very efficiently made most of the splints, and Messrs. Matthews Brothers, of Careystreet, are the London makers. It has been used by myself and others in nearly thirty cases : for example, after excision of the elbow, in cases of injury to the elbow, especially when attended with much swelling; in disease of the elbow, or where bony anchylosis is desired, and in fractures about the joint without much displacement-e.g., fracture of the head of the radius. It may be used in any case where complete immobility of the joint is desired. It is very comfortable, and patients who have worn it prefer it to others. In one case it was worn continuously for eight months, and after its use in a case of synovitis of the elbow, where the limb was bandaged to a wooden splint, an immediate improvement took place. It is not taken off at night, and when the shoulderpiece is concealed under the armhole of the waistcoat or other article of dress, it is hardly possible to see that the patient is wearing any apparatus, the hand, kept in position by a bandage carried over the wrist from side to side of the lower part of the splint, being the most prominent figure.

Huddersfield.

\section{9. dittirtor}

\section{HOSPITAL PRACTICE, BRITISH AND FOREIGN.}

Nulla antem est alia pro certo noscendi via, nisi quamplurimas et morborum ot dissectionum historias, tum aliorum tum proprias collectas habere, et inter se comparare.-Mosqagri De Sed. et Caus. Morb., lib.iv. Procmium.

\section{ROYAL LONDON OPHTHALMIC HOSPITAL, MOORFIELDS.}

TWO CASES OF SARCOMA OF CHOROID ; ONF OF TRAUMATIC H EMORRHAGE INTO THE VITREOUS.

(Under the care of Mr. STREatfeild.)

For the following notes we are indebted to Dr. Silcock, clinical assistant.

CASE 1. Sarcoma of Choroid. - J. B-, aged seventy, pilot, a hale old man, well preserved for his age, attended the out-patient department on Jan. 3rd, having lost the sight in 